\title{
Long-term incidence and risk factors for development of spinal deformity following resection of pediatric intramedullary spinal cord tumors
}

\author{
Clinical article
}

\author{
Raheel Ahmed, M.D., Ph.D., ${ }^{1}$ Arnold H. Menezes, M.D., ${ }^{1}$ Olatilewa O. Awe, M.D., ${ }^{1}$ \\ Kelly B. Mahaney, M.D., ${ }^{1}$ James C. Torner, Ph.D., ${ }^{2}$ and Stuart L. Weinstein, M.D. ${ }^{3}$ \\ Departments of ${ }^{1}$ Neurosurgery, ${ }^{2}$ Epidemiology, and ${ }^{3}$ Orthopedics and Rehabilitation, University of Iowa \\ Hospitals and Clinics, Iowa City, Iowa
}

\begin{abstract}
Object. Spinal deformity in pediatric patients with intramedullary spinal cord tumors (IMSCTs) may be either due to neurogenic disability or due to secondary effects of spinal decompression. It is associated with functional decline and impairment in health-related quality-of-life measures. The authors sought to identify the long-term incidence of spinal deformity in individuals who had undergone surgery for IMSCTs as pediatric patients and the risk factors and overall outcomes in this population.

Methods. Treatment records for pediatric patients (age $<21$ years) who underwent surgical treatment for histology-proven primary IMSCTs between 1975 and 2010 were reviewed. All patients were evaluated in consultation with the pediatric orthopedics service. Clinical records were reviewed for baseline and follow-up imaging studies, surgical fusion treatment, and long-term skeletal and disease outcomes.

Results. The authors identified 55 patients (30 males and 25 females) who were treated for pediatric IMSCTs between January 1975 and January 2010 . The mean duration of follow-up ( \pm SEM) was $11.4 \pm 1.3$ years (median 9.3 years, range $0.2-37.2$ years). Preoperative skeletal deformity was diagnosed in 11 (20\%) of the 55 patients, and new-onset postoperative deformity was noted in $9(16 \%)$. Conservative management with observation or external bracing was sufficient in $8(40 \%)$ of these 20 cases. Surgical fusion was necessary in $11(55 \%)$. Posterior surgical fusion was sufficient in $6(55 \%)$ of these 11 cases, while combined anterior and posterior fusion was undertaken in $5(45 \%)$. Univariate and multivariate analysis of clinical and surgical treatment variables indicated that preoperative kyphoscoliosis $(p=0.0032)$ and laminectomy/laminoplasty at more than 4 levels $(p=0.05)$ were independently associated with development of spinal deformity that necessitated surgical fusion. Functional scores and 10-year disease survival outcomes were similar between the 2 groups.

Conclusions. Long-term follow-up is essential to monitor for delayed development of spinal deformity, and regular surveillance imaging is recommended for patients with underlying deformity. The authors' extended follow-up highlights the risk factors associated with development of spinal deformity in patients treated for pediatric IMSCTs. Surgical fusion allows patients who develop progressive deformity to achieve long-term functional and survival outcomes comparable to those of patients who do not develop progressive deformity.
\end{abstract}

(http://thejns.org/doi/abs/10.3171/2014.1.PEDS13317)

KEY WORDS
fusion $\quad$ intramedullary tumors $\bullet \quad$ laminoplasty $\bullet \quad$ spinal deformity

A DVANCEMENTS in neurosurgical techniques and neurophysiological monitoring have enabled improvements in resection of pediatric intramedullary spinal cord tumors (IMSCTs). This has enabled improved tumor control with favorable disease survival and neurological function outcomes. These surgical approaches are complicated, however, by the development of secondary spinal deformity. Spinal deformity associated with the development and treatment of pediatric IMSCT is an impor-

\footnotetext{
Abbreviations used in this paper: $\mathrm{IMSCT}=$ intramedullary spinal cord tumor; XRT = radiation therapy.
}

tant determinant of overall disease outcomes. Progression in spinal deformity is directly linked with health-related quality of life measures and functional scores..$^{26,31}$

There is wide variation in the pediatric incidence of postlaminectomy deformity following resection of intramedullary tumors, ranging from $24 \%$ to $100 \%$. $^{3,5,7,12,16 \text {, }}$ 27,29,33,35

The pathogenesis of secondary spinal deformity for these patients is unlike the development of iatrogenic postlaminectomy kyphosis in adults undergoing cervical decompression for cervical myelopathy, given the unique biomechanical properties of the spine in this age group. 


\section{R. Ahmed et al.}

Neuromuscular dysfunction associated with the underlying intramedullary tumor may contribute to neurogenic spinal deformity at baseline. ${ }^{16,33}$ Ligamentous structures provide predominant biomechanical stability in the face of skeletal immaturity in this age group and may be disrupted by surgical intervention. ${ }^{2}$ Ventral subluxation due to loss of dorsal laminae and musculoligamentous support may also contribute to deformity. ${ }^{17}$ The pubertal growth spurt may further aggravate spinal deformity. ${ }^{33}$ Postlaminectomy kyphosis in children may develop through increased load bearing on anterior elements leading to wedging of vertebral bodies.

Various measures, including closer surveillance, concurrent fusion in patient subgroups at risk, and osteoplastic laminoplasties, have been advocated to address adverse consequences of secondary deformity., $4,18,27,28$ Studies to date focusing on the comparative roles of spinal laminectomy versus osteoplastic laminoplasty have been limited by short-term follow-up. ${ }^{18}$ Studies have documented onset of postoperative deformity at 1.8-7 years following spinal laminectomy. ${ }^{22,35}$ Moreover, onset of deformity following adjunct radiation therapy (XRT) is typically delayed. ? Even after attainment of skeletal maturity and final growth, there is continued risk of deformity progression. Given the risk of deformity progression in pediatric patients, often extending into adulthood, long-term assessment of spinal deformity is essential to effectively monitor the delayed development and/or progression of spinal deformity and to characterize disease outcomes. Extended follow-up of our study group, beyond the 1st decade, enables us to address long-term spinal growth patterns past the adolescent growth spurt.

This article is the second of 2 companion articles being published together. In the first article, ${ }^{1}$ we reported on the clinical and treatment determinants affecting longterm disease survival and neurological outcomes in the same group of patients reported on in the present paper. In this second article, our goal was therefore to determine the long-term consequences of spinal decompression and resection of IMSCTs on spinal alignment and secondary deformity in the pediatric age group.

\section{Methods}

This retrospective study was approved by the University of Iowa Human Subjects Office Institutional Review Board.

Pediatric patients (age $<21$ years at presentation) with a histopathological diagnosis of IMSCT were identified through a retrospective search of the neurosurgery inpatient database at the University of Iowa Hospitals and Clinics for the period from January 1975 to January 2010. Patient records were reviewed for: 1) patient demographics, 2) clinical presentation, 3) surgical treatment received, 4) chemotherapy and/or radiation therapy, and 5) final clinical outcome (based on clinical and radiographic evaluation by the Neurosurgery and Pediatric Oncology and Pediatric Orthopedic Services).

Case records were reviewed to obtain demographic, clinical, radiographic, treatment, and follow-up details. Baseline and follow-up clinical and radiographic assess- ment of skeletal deformity and determination and timing of skeletal fusion when needed were undertaken in consultation with the Pediatric Orthopedics Service. Patients who developed progressive deformity on interval imaging despite external bracing were considered for deformity correction surgery.

Deficit score on presentation was calculated through the presence or absence of motor, sensory, bladder, or bowel deficits, with the presence of each deficit counting for 1 point, such that the scores could range from 0 (no deficits) to 4 (deficits in each category). If either C-7 or $\mathrm{T}-1$ was involved in the laminectomy, the cervicothoracic junction was considered to be involved. If either T-12 or L-1 was involved in the laminectomy, the thoracolumbar junction was considered to be involved.

In treating patients with IMSCTs at our institution, an osteoplastic laminoplasty is planned unless preoperative imaging studies indicate significant mass effect that necessitates extensive decompression, often with the aid of a fascial graft, or in cases in which preoperative imaging studies indicate a high probability of incomplete resection given a lack of clearly defined tumor margins.

\section{Statistical Analysis}

Progression-free and disease-survival rates were determined with Kaplan-Meier survival estimates and 95\% confidence intervals. Statistical associations were assessed by means of log-rank Mantel Cox analysis using GraphPad Prism version 5.04 for Windows and SAS version 9.3. Statistical significance was determined at alpha $\leq 0.05$.

\section{Results}

A total of 55 patients (30 male [55\%] and 25 female [45\%]) were selected over the study period from 1975 to 2010. Their mean age at presentation was $10 \pm 1$ years (range $0.5-21$ years).

Astrocytomas were the most prevalent histological tumor subtype, present in $53 \%$ of the cases $(n=29)$, followed by ependymomas $(22 \%, \mathrm{n}=12)$ and gangliogliomas $(13 \%, \mathrm{n}=7)$. The tumors were predominantly low grade (43 tumors [78\%]). High-grade tumors were diagnosed in $22 \%$ of the study group (12 patients).

\section{Skeletal Deformity}

The incidence of preoperative, baseline skeletal deformity as evident on preoperative imaging was 20\% (11 of 55 cases). New-onset postoperative skeletal deformity was noted in $16 \%$ of the patients ( 9 of 55). Nonoperative management with observation or external bracing was sufficient in $40 \%$ (8) of the 20 patients with pre- or postoperative skeletal deformity. Surgical fusion was necessary in $55 \%$ (11 patients); resolution was noted in 1 patient (5\%).

Of the 10 patients with significant kyphosis, 4 (40\%) were treated conservatively, while the remaining $6(60 \%)$ underwent surgical fusion procedures. The mean kyphotic angle deformity in the conservatively treated group was $40^{\circ} \pm 8^{\circ}\left(\right.$ range $\left.30^{\circ}-64^{\circ}\right)$, as compared with $80^{\circ} \pm$ $8^{\circ}$ (range $\left.47^{\circ}-105^{\circ}\right)$ in the surgically treated group $(\mathrm{p}=$ 


\section{Skeletal deformity and pediatric intramedullary tumors}

0.007). Of the 18 patients with scoliosis, 5 (28\%) were treated conservatively and $13(72 \%)$ were treated surgically. The mean scoliotic deformity measured $27^{\circ} \pm 7^{\circ}$ (range $10^{\circ}-50^{\circ}$ ) in the conservatively managed group as compared with $60^{\circ} \pm 9^{\circ}$ (range $16^{\circ}-110^{\circ}$ ) in the surgically treated group $(\mathrm{p}=0.04)$.

\section{Surgical Treatment}

Surgical treatment details are summarized in Table 1. A total of 43 patients $(78 \%)$ underwent surgical laminectomy, while 12 patients (22\%) underwent laminoplasty. The average age of patients in the 2 groups was similar $-8.8 \pm 1.8$ years in laminoplasty group and 10.3 \pm 1.1 years in laminectomy group $(\mathrm{p}=0.5078)$. The number of spinal levels involved was also similar: a mean $( \pm$ SEM) of $4.1 \pm 0.3$ in the laminoplasty group and $4.7 \pm$ 0.5 in the laminectomy group $(p=0.4841)$. Spinal fusion procedures were performed in $9(21 \%)$ of the 43 patients who underwent spinal laminectomy and 2 (17\%) of the 12 patients who underwent osteoplastic laminoplasty $(\mathrm{p}=$ 0.7179; Table 2).

Of the 11 patients who underwent surgical fusion for spinal deformity, 7 (64\%) had preoperative kyphoscoliosis. The other 4 patients (37\%) developed clinically significant kyphoscoliosis at a mean interval of 26 months (range 2-84 months) postoperatively. Preoperative baseline surgical deformity characteristics included a mean kyphotic deformity of $63^{\circ} \pm 12^{\circ}$ in 3 patients (range $41^{\circ}-$ $82^{\circ}$ ) and $49^{\circ} \pm 9^{\circ}$ scoliosis in the other 4 patients (range $32^{\circ}-70^{\circ}$ scoliosis).

Eight of 11 patients $(73 \%)$ with surgically treated deformity underwent a single fusion procedure, while the remaining 3 patients (27\%) underwent 2 fusion procedures. Within the latter group, the underlying spinal deformity had progressed despite the initial fusion procedure. The mean interval between tumor resection and surgical fusion was $4.4 \pm 0.9$ years in the postoperative period (range 0.7-10 years). Posterior surgical fusion was sufficient in 6 patients $(55 \%)$, while combined anterior and posterior fusion was undertaken in $5(45 \%)$.

\section{Long-Term Outcomes}

The mean follow-up period $( \pm$ SEM) for the study group was $11.4 \pm 1.3$ years (median 9.3 years, interquartile range 3.8-15.5 years, overall range 0.2-37.2 years). Univariate and multivariate analyses of the clinical and surgical treatment variables indicated that preoperative kyphoscoliosis $(\mathrm{p}=0.0032)$ and laminectomy/laminoplasty spanning more than 4 levels $(\mathrm{p}=0.05)$ was independently associated with a higher risk of developing spinal deformity that necessitates surgical fusion (Table 2).

The proportion of patients with normal or mild functional limitations (McCormick Grades I-II) was similar in the subgroup that underwent deformity correction surgery (8 [72\%] of 11 patients) and those who did not develop surgical deformity (40 [90\%] of 44, $\mathrm{p}=0.1056$ ). Overall survival was not significantly different between the group of patients who underwent deformity correction surgery and those who did not require surgical fusion. The 10 -year overall survival rate was $91 \%$ (95\% CI
TABLE 1: Summary of surgical treatment*

\begin{tabular}{|c|c|}
\hline Variable & Value \\
\hline \multicolumn{2}{|l|}{ no. of tumor surgeries } \\
\hline 1 & $39(71)$ \\
\hline 2 & $11(20)$ \\
\hline $3-4$ & $5(9)$ \\
\hline \multicolumn{2}{|l|}{ extent of resection } \\
\hline GTR & $21(38)$ \\
\hline STR & $34(62)$ \\
\hline LM & $43(78)$ \\
\hline mean no. of levels & 4.1 \\
\hline range of no. of levels & $1-11$ \\
\hline LP & $12(22)$ \\
\hline mean no. of levels & 4.7 \\
\hline range of no. of levels & $3-6$ \\
\hline \multicolumn{2}{|l|}{ spinal level for LP/LM } \\
\hline cervicomedullary & $4(7)$ \\
\hline cervical & $16(29)$ \\
\hline cervicothoracic $\dagger$ & $5(9)$ \\
\hline thoracic & $15(27)$ \\
\hline thoracolumbar $\ddagger$ & $13(24)$ \\
\hline lumbar & $2(4)$ \\
\hline \multicolumn{2}{|l|}{ no. of myelotomy levels } \\
\hline mean \pm SEM & $3.7 \pm 0.2$ \\
\hline range & $1-9$ \\
\hline \multicolumn{2}{|l|}{ onset of deformity } \\
\hline preexistent & $11(20)$ \\
\hline postop & $9(16)$ \\
\hline \multicolumn{2}{|c|}{ time from op to onset of postop deformity } \\
\hline mean \pm SEM & $18 \pm 9$ \\
\hline range & $0-84$ \\
\hline \multicolumn{2}{|c|}{ course of preexistent deformity $(n=11)$} \\
\hline observation/bracing & $4(36)$ \\
\hline surgery & $7(64)$ \\
\hline \multicolumn{2}{|l|}{ course of postop deformity $(n=9)$} \\
\hline observation/bracing & $4(44)$ \\
\hline surgery & $4(44)$ \\
\hline resolution & $1(12)$ \\
\hline \multicolumn{2}{|l|}{ management of deformity $(n=20)$} \\
\hline observation/bracing & $8(40)$ \\
\hline surgery & $11(55)$ \\
\hline resolution & $1(5)$ \\
\hline \multicolumn{2}{|c|}{ time interval from tumor resection to fusion surgery (yrs) } \\
\hline mean \pm SEM & $4.5 \pm 0.9$ \\
\hline range & $0.7-10$ \\
\hline \multicolumn{2}{|l|}{ no. of fusion surgeries $(n=11)$} \\
\hline 1 & $8(72)$ \\
\hline$>1$ & $3(28)$ \\
\hline
\end{tabular}

(continued) 


\section{R. Ahmed et al.}

\section{TABLE 1: Summary of surgical treatment* (continued)}

* Values represent numbers of cases (\%) unless otherwise indicated. GTR = gross-total resection; LM = laminectomy; LP = laminoplasty; STR $=$ subtotal resection.

† If either C-7 or T-1 was involved in the laminectomy, the cervicothoracic junction was considered to be involved.

‡ If either T-12 or L-1 was involved in the laminectomy, the thoracolumbar junction was considered to be involved.

$51 \%-98 \%$ ) for patients with surgical deformity as compared with $69 \%(95 \%$ CI $50 \%-83 \%)$ for patients without surgical deformity $(\mathrm{p}=0.4545)$ (Fig. 1).

\section{Discussion}

Our results highlight the long-term incidence of and risk factors for spinal deformity in patients with pediatric IMSCTs. Development of secondary deformity is associated with functional decline, with neurological deficits developing due to spinal cord compression. ${ }^{33}$ In turn, the resultant neurological decline tends to aggravate the skeletal deformity. In this respect, long-term follow-up of pediatric patients with IMSCTs is essential, given the immediate and delayed lifetime risk of progressive skeletal deformity of the developing spine. Extended follow-up of our study cohort, for the first time beyond the 1st decade, enabled us to undertake long-term assessment. Our results indicate that the long-term risk of developing surgical deformity is $20 \%$ and is significantly associated with spinal decompression extending beyond 4 spinal segments and with preexisting spinal deformity. Long-term survival and functional outcomes were not adversely affected by the secondary development and surgical treatment of spinal deformity.

\section{Preoperative Deformity}

In our study group, the overall prevalence of underlying deformity on presentation was $20 \%$. This is similar to previous reports of preoperative deformity in up to $33 \%$ of patients..$^{16,33}$ Our results indicate that preoperative spinal deformity, when present, is most significantly associated with the lifetime risk of developing progressive deformity that necessitates surgical fusion. In our series, the incidence of surgical fusion within the subgroup of patients with underlying deformity on presentation was 64\%. Preoperative spinal deformity, when present, has also been previously reported to be an independent risk factor for progressive deformity following surgery. ${ }^{12,33}$

The pathogenesis of spinal deformity on presentation in patients with IMSCTs is in part due to the underlying neuromuscular dysfunction. This in turn predisposes to development or progression of postoperative spinal deformity. ${ }^{11}$ Irreversible changes in musculoskeletal loading may also persist despite resection of IMSCTs. Of note, the functional grade on presentation was not significantly different in the two groups in our study group. This indicates that functional grade assessment may not correlate with underlying neurogenic disability that leads to skeletal deformity.

\section{Osteoplastic Laminoplasty and Risk of Spinal Deformity}

Osteoplastic laminoplasties have been proposed to reduce the risk of future development of spinal deformity. The postulated protective effects include restoration of the posterior tension band and bony re-fusion leading to structural reestablishment of spinal integrity. Through reattachment of the paraspinous musculature, laminoplasty may also decrease the incidence of postoperative musculoskeletal pain. ${ }^{6}$ In pediatric IMSCT patients, the overall incidence of progressive spinal deformity was reported to be 5\% in patients treated with laminoplasty as compared with $30 \%$ in patients having undergone a laminectomy. ${ }^{18}$ Although both groups had similar functional outcomes at most recent follow-up, this study reported a beneficial role for laminoplasty in averting postoperative spinal deformity.

Nevertheless, data regarding the role of laminoplasty in averting the risk of postoperative deformity are conflicting.

A meta-analysis of postoperative spinal deformity following laminoplasty indicated significant rates of progression in cervical deformity (35\%) as well as de novo postoperative kyphosis (10\%), indicating limited efficacy of laminoplasties in averting future progression of deformity. ${ }^{24}$ Other studies with pooled data from spinal tumor resections within all age groups have demonstrated similar rates of deformity between these two comparison groups. ${ }^{19}$ Previous studies may have been limited by the short duration of follow-up and may have underestimated the true long-term incidence of deformity in these patients. ${ }^{18,19}$

In our opinion, the definitive benefits of laminoplasty are yet to be proven. Laminoplasty may possibly reduce the incidence of deformity, without completely eliminating the lifetime risk of postoperative deformity, as evident on our extended follow-up. It may still be recommended since it may promote wound healing and reduce postoperative CSF leaks without incurring any significant additional morbidity. $19,20,36$ Importantly, it provides a safer extradural plane of surgical dissection during exposure in patients who undergo repeat resections.

\section{Role of Skeletal Factors in Postoperative Deformity}

Our results indicate that spinal decompression extending beyond 4 spinal segments is also associated with the risk of progressive deformity over long-term follow-up ( $\mathrm{p}$ $=0.05$ approaches significance). The risk of postoperative deformity or instability has been shown to correlate with the total span of the laminectomy defect, preservation of facet joint integrity, 12,22,37 and preoperative loss of cervical lordosis. ${ }^{11}$ Additional risk factors identified in other studies include presence of a tumor-associated syrinx and preoperative spinal deformity. ${ }^{33}$ The latter, in particular, may be associated with irreversible changes in musculoskeletal loading that may persist despite resection of intramedullary tumor. Yet other studies have shown that the extent of bony removal, including facetectomy, does not correlate with the incidence of postoperative spinal deformity in children. ${ }^{34}$

The risk of deformity in the pediatric age group is 
Skeletal deformity and pediatric intramedullary tumors

TABLE 2: Factors determining operative deformity*

\begin{tabular}{|c|c|c|c|c|c|}
\hline \multirow[b]{2}{*}{ Characteristic } & \multicolumn{2}{|c|}{ Surgical Deformity } & \multirow[b]{2}{*}{ Total } & \multirow{2}{*}{$\begin{array}{c}\text { Univariate Analysis } \\
\text { p Value }\end{array}$} & \multirow{2}{*}{$\begin{array}{l}\text { Multivariate Analysis } \\
\text { p Value }\end{array}$} \\
\hline & Present & Absent & & & \\
\hline \multicolumn{6}{|l|}{ patient age at presentation } \\
\hline$<5$ yrs & $5(25)$ & $15(75)$ & $20(36)$ & 0.2111 & \\
\hline $6-13$ yrs & $5(28)$ & $13(72)$ & $18(33)$ & & \\
\hline $14-21$ yrs & $1(6)$ & $16(94)$ & $17(31)$ & & \\
\hline \multicolumn{5}{|l|}{ tumor pathology } & histological type \\
\hline astrocytoma & $8(26)$ & $23(74)$ & $31(56)$ & 0.2211 & \\
\hline other† & $3(13)$ & $21(87)$ & $24(44)$ & & \\
\hline \multicolumn{6}{|l|}{ grade } \\
\hline high grade & $1(8)$ & $11(92)$ & $12(22)$ & 0.2532 & \\
\hline low grade & $10(24)$ & $33(77)$ & $43(78)$ & & \\
\hline \multicolumn{6}{|c|}{ clinical presentation } \\
\hline \multicolumn{6}{|c|}{ time from Sx onset to presentation in mos } \\
\hline mean & 7.7 & 7.2 & 7.3 & 0.8949 & \\
\hline range & $0.7-14.7$ & $3.9-10.5$ & $4.4-10.2$ & & \\
\hline \multicolumn{6}{|l|}{ motor deficit } \\
\hline present & $7(21)$ & $26(79)$ & $33(60)$ & 0.8473 & \\
\hline absent & $4(18)$ & $18(82)$ & $22(40)$ & & \\
\hline \multicolumn{6}{|l|}{ sensory deficit } \\
\hline present & $9(21)$ & $33(79)$ & $42(76)$ & 0.7179 & \\
\hline absent & $2(15)$ & $11(85)$ & $13(24)$ & & \\
\hline \multicolumn{6}{|l|}{ bladder deficit } \\
\hline present & $3(14)$ & $18(86)$ & $21(38)$ & 0.3758 & \\
\hline absent & $8(24)$ & $26(76)$ & $34(62)$ & & \\
\hline \multicolumn{6}{|l|}{ bowel deficit } \\
\hline present & $3(30)$ & $7(70)$ & $10(18)$ & 0.4022 & \\
\hline absent & $8(18)$ & $37(82)$ & $45(82)$ & & \\
\hline \multicolumn{6}{|l|}{ deficit score } \\
\hline$\leq 2$ & $8(21)$ & $31(79)$ & $39(71)$ & 0.8820 & \\
\hline$>2$ & $3(19)$ & $13(81)$ & $16(29)$ & & \\
\hline \multicolumn{6}{|c|}{ functional grade on presentation } \\
\hline$|-| \mid$ & $6(16)$ & $31(84)$ & $37(67)$ & 0.3145 & \\
\hline III-V & $5(28)$ & $13(72)$ & $18(33)$ & & \\
\hline \multicolumn{6}{|l|}{ preop kyphoscoliosis } \\
\hline present & $7(64)$ & $4(36)$ & $11(20)$ & $<0.0001$ & 0.0032 \\
\hline absent & $4(9)$ & $40(91)$ & $44(80)$ & & \\
\hline \multicolumn{6}{|l|}{ tumor location } \\
\hline cervical & $6(22)$ & $21(78)$ & $27(49)$ & 0.5024 & \\
\hline thoracic & $5(22)$ & $18(78)$ & $23(42)$ & & \\
\hline lumbar & $0(0)$ & $5(100)$ & $5(9)$ & & \\
\hline \multicolumn{6}{|l|}{ syrinx } \\
\hline yes & $4(25)$ & $12(75)$ & $16(36)$ & 0.2127 & \\
\hline no & $3(11)$ & $25(89)$ & $28(64)$ & & \\
\hline \multicolumn{6}{|l|}{ margins } \\
\hline circumscribed & $1(7)$ & $14(93)$ & $15(34)$ & 0.2280 & \\
\hline diffuse & $6(21)$ & $23(79)$ & $29(66)$ & & \\
\hline
\end{tabular}

(continued) 


\section{R. Ahmed et al.}

TABLE 2: Factors determining operative deformity* (continued)

\begin{tabular}{|c|c|c|c|c|c|}
\hline \multirow[b]{2}{*}{ Characteristic } & \multicolumn{2}{|c|}{ Surgical Deformity } & \multirow[b]{2}{*}{ Total } & \multirow{2}{*}{$\begin{array}{l}\text { Univariate Analysis } \\
\text { p Value }\end{array}$} & \multirow{2}{*}{$\begin{array}{l}\text { Multivariate Analysis } \\
\text { p Value }\end{array}$} \\
\hline & Present & Absent & & & \\
\hline \multicolumn{6}{|l|}{$\begin{array}{l}\text { clinical presentation (continued) } \\
\text { enhancement }\end{array}$} \\
\hline yes & $7(18)$ & $33(88)$ & $40(91)$ & 0.3616 & \\
\hline no & $0(0)$ & $4(100)$ & $4(9)$ & & \\
\hline \multicolumn{6}{|l|}{ no. of levels spanned } \\
\hline $1-3$ & $2(9)$ & $20(91)$ & $22(40)$ & 0.2473 & \\
\hline $4-6$ & $6(26)$ & $17(74)$ & $23(42)$ & & \\
\hline$>7$ & $3(30)$ & $7(70)$ & $10(18)$ & & \\
\hline \multicolumn{6}{|l|}{$\begin{array}{l}\text { surgical treatment } \\
\text { resection }\end{array}$} \\
\hline GTR & $3(14)$ & $18(86)$ & $21(38)$ & 0.4051 & \\
\hline STR & $8(24)$ & $26(76)$ & $34(62)$ & & \\
\hline \multicolumn{6}{|l|}{ shunt placement } \\
\hline yes & $4(33)$ & $8(67)$ & $12(22)$ & 0.1916 & \\
\hline no & $7(16)$ & $36(84)$ & $43(78)$ & & \\
\hline \multicolumn{6}{|l|}{ no. of tumor surgeries } \\
\hline 1 & $7(18)$ & $32(82)$ & $39(71)$ & 0.5527 & \\
\hline$>1$ & $4(25)$ & $12(75)$ & $16(29)$ & & \\
\hline \multicolumn{6}{|l|}{ spinal decompression } \\
\hline LM & $9(21)$ & $33(79)$ & $42(78)$ & 0.7179 & \\
\hline LP & $2(17)$ & $10(83)$ & $12(22)$ & & \\
\hline \multicolumn{6}{|l|}{ no. of levels w/ LM or LP } \\
\hline$\leq 4$ & $2(7)$ & $28(93)$ & $30(56)$ & 0.0052 & 0.05 \\
\hline$>4$ & $9(38)$ & $15(63)$ & $24(44)$ & & \\
\hline mean no. of levels w/ LM/LP $( \pm$ SEM) & $6 \pm 0.8$ & $4 \pm 0.4$ & $4.6 \pm 0.4$ & 0.0251 & \\
\hline \multicolumn{6}{|l|}{ spinal level of LM/LP } \\
\hline cervical & $6(24)$ & $19(76)$ & $25(45)$ & 0.6602 & \\
\hline thoracic & $5(18)$ & $23(82)$ & $28(51)$ & & \\
\hline lumbar & $0(0)$ & $2(100)$ & $2(4)$ & & \\
\hline \multicolumn{6}{|l|}{ LM/LP involves spinal transition levelł } \\
\hline yes & $4(18)$ & $18(82)$ & $22(40)$ & 0.7831 & \\
\hline no & $7(21)$ & $26(79)$ & $33(60)$ & & \\
\hline $\begin{array}{l}\text { mean no. of surgical myelotomy levels } \\
\quad( \pm \text { SEM })\end{array}$ & $4 \pm 0.5$ & $3.6 \pm 0.3$ & $3.7 \pm 0.3$ & 0.3486 & \\
\hline \multicolumn{6}{|l|}{ spinal levels of myelotomy } \\
\hline cervical & $6(25)$ & $18(75)$ & $24(44)$ & 0.4936 & \\
\hline thoracic & $5(19)$ & $22(81)$ & $27(49)$ & & \\
\hline lumbar & $0(0)$ & $4(100)$ & $4(7)$ & & \\
\hline \multicolumn{6}{|l|}{ onset of deformity } \\
\hline preop & $3(50)$ & $3(50)$ & $6(11)$ & $<0.0001$ & \\
\hline postop & $8(62)$ & $5(38)$ & $13(24)$ & & \\
\hline none & $0(0)$ & $36(100)$ & $36(65)$ & & \\
\hline \multicolumn{6}{|l|}{ clinical outcomes } \\
\hline \multicolumn{6}{|l|}{ course at last follow-up } \\
\hline stable & $1(13)$ & $7(87)$ & $8(15)$ & 0.7602 & \\
\hline decline & $3(18)$ & $14(82)$ & $17(31)$ & & \\
\hline improvement & $7(23)$ & $23(77)$ & $30(55)$ & & \\
\hline
\end{tabular}

(continued) 
Skeletal deformity and pediatric intramedullary tumors

TABLE 2: Factors determining operative deformity* (continued)

\begin{tabular}{|c|c|c|c|c|c|}
\hline \multirow[b]{2}{*}{ Characteristic } & \multicolumn{2}{|c|}{ Surgical Deformity } & \multirow[b]{2}{*}{ Total } & \multirow{2}{*}{$\begin{array}{c}\text { Univariate Analysis } \\
\text { p Value }\end{array}$} & \multirow{2}{*}{$\begin{array}{c}\text { Multivariate Analysis } \\
\text { p Value }\end{array}$} \\
\hline & Present & Absent & & & \\
\hline \multicolumn{6}{|l|}{ clinical outcomes (continued) } \\
\hline \multicolumn{6}{|l|}{ functional status at last follow-up } \\
\hline$|-| \mid$ & $8(17)$ & $40(83)$ & $48(87)$ & 0.1056 & \\
\hline III-V & $3(43)$ & $4(57)$ & $7(13)$ & & \\
\hline \multicolumn{6}{|l|}{ adjuvant therapy } \\
\hline \multicolumn{6}{|l|}{ type of therapy } \\
\hline chemo w/ or w/o XRT & $4(17)$ & $19(83)$ & $23(42)$ & 0.6818 & \\
\hline none & $7(22)$ & $25(78)$ & $32(58)$ & & \\
\hline \multicolumn{6}{|l|}{ indication for chemo } \\
\hline not used & $8(21)$ & $31(79)$ & $39(72)$ & 0.9666 & \\
\hline adjuvant or recurrence therapy & $3(20)$ & $12(80)$ & $15(28)$ & & \\
\hline \multicolumn{6}{|l|}{ indication for XRT } \\
\hline not used & $3(11)$ & $24(89)$ & $27(49)$ & 0.1056 & \\
\hline adjuvant or recurrence therapy & $8(29)$ & $20(71)$ & $28(51)$ & & \\
\hline
\end{tabular}

* Values represent numbers of cases (\%) unless otherwise indicated. chemo = chemotherapy; Sx = symptom.

$\dagger$ Includes ependymomas, ganglogliomas, and other histopathology subtypes.

$\ddagger$ Involvement of cervicothoracic or thoracolumbar region.

higher for patients with cervical tumors, ${ }^{35}$ although it can occur after surgery at any spinal level. ${ }^{7}$ Other studies have shown higher rates of secondary deformity with thoracolumbar tumor locations. ${ }^{33,36}$ The risk of secondary deformity is especially high in the pediatric age group. $7,12,16,22,34,35$ The underlying ligamentous laxity, reduced paraspinal musculature support, horizontal orientation of the facet joints, and disproportionate load bearing due to the relative cranium to body mass ratio have all been known to underlie the susceptibility of the pediatric spine. ${ }^{2}$ Age less than 13 years may be an independent risk factor for secondary deformity ${ }^{33,35}$ and may additionally be independent of the extent of bony resection or history of irradiation. ${ }^{34}$ Heterogeneity in the pathogenic role of these factors may be due to differences in patient popula-

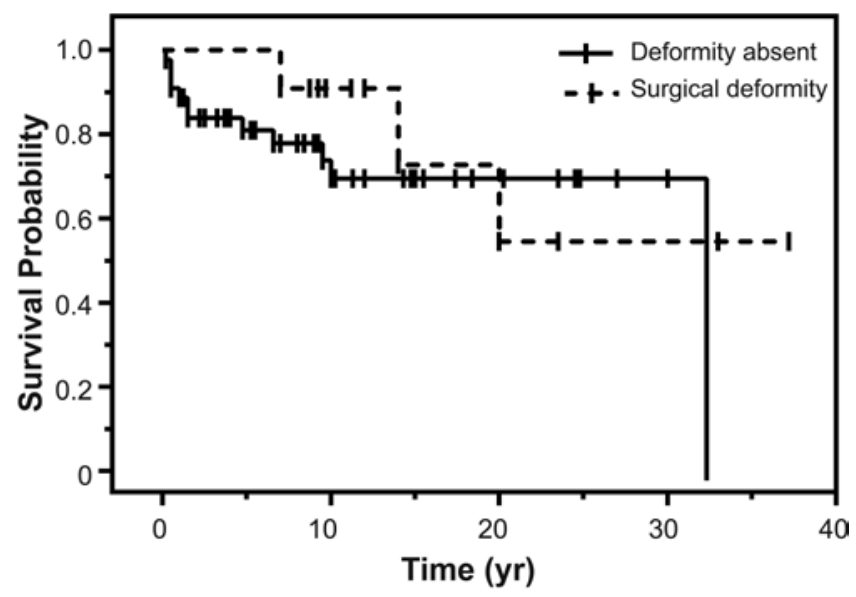

FIG. 1. Comparison of disease survival between patients with (dashed line) and without (solid line) surgical deformity, as determined with the Kaplan-Meier method. Vertical hatches indicate censored events. The $p$ value was nonsignificant. tion and variation in tumor grade, preoperative neurological disability, and adjunct treatment factors.

\section{Role of Concurrent Fusion}

Laminoplasty with concurrent posterolateral fusion has been reported to decrease the incidence of postoperative deformity. ${ }^{4,27}$ However, concurrent posterior fusion has been documented to decrease the development of postlaminectomy kyphosis only within the subset of pediatric patients with no evidence of tumor progression or recurrence. ${ }^{28}$ The protective effects of prophylactic fusion were lost when deformity rates were pooled from the entire study group. ${ }^{4}$

There are limitations of the prophylactic fusion approach in pediatric IMSCT patients. Disease recurrence leading to neuromuscular scoliosis can negate any beneficial effects of the posterior structural fusion. This approach is hence limited, given the natural history of pediatric IMSCTs that are complicated by recurrence. ${ }^{10,13,32}$ Additionally, the presence of posterior fusion following laminectomy is associated with the risk of "crank-shaft" deformity in skeletally immature children, due to continued growth of the anterior spine column and a high rate of pseudarthrosis. ${ }^{15,25}$ Conversely, anterior augmentation of spinal fusion can halt deformity progression, but it is associated with significant operative morbidity that is difficult to justify on a prophylactic basis in pediatric IMSCT patients..$^{14,23}$

\section{Effects of XRT}

Radiation therapy is independently associated with a higher risk for posttreatment deformity, even in patients with no history of spinal decompression or laminectomy. ${ }^{8,30}$ Radiation-induced damage to the growth plate leads to decreased growth potential. Irregular growth patterns can 


\section{R. Ahmed et al.}

result from asymmetrical involvement of the growth plate, with resultant progression in spinal deformity. ${ }^{7,35}$ Onset of postradiation spinal deformity is later when compared with postlaminectomy cases (mean of 77 months post-XRT vs 5-15 months following surgical laminectomy). ${ }^{7}$ The risk of secondary deformity is probably compounded in patients who undergo laminectomy and XRT. ${ }^{21}$

\section{External Orthosis}

The efficacy of external orthosis in averting the subsequent development of spinal deformity is unclear. Postoperative bracing may help delay the onset of progression without reducing the overall risk of developing postoperative deformity. ${ }^{21}$ Postoperative bracing may be necessary following laminoplasty to promote anatomical alignment of the laminae block. ${ }^{21}$ It should also be used following fusion procedures until bony fusion occurs. In our series, 10 of 13 patients with postoperative braces needed fusion surgery. We recommend bracing in all patients who undergo surgical fusion, in patients with mild scoliotic defects, and as an adjunctive treatment to delay surgical fusion, when feasible, in patients before their adolescent growth spurt.

\section{Conclusions}

Late neurological deterioration following development of postlaminectomy kyphosis has been well described $^{17}$ and is attributed, in part, to spinal compression from anterior draping over the kyphotic deformity. Correction of deformity aids in cosmesis and improves psychological development in children. ${ }^{31}$ It is also associated with significant improvement in pulmonary function. ${ }^{26}$ Treatment options include anterior approaches for kyphotic deformities, which are typically supplanted by posterior fusion for more complex deformity curves. ${ }^{9}$ Long-term follow-up is essential to monitor for delayed development of spinal deformity, and surveillance imaging is needed for patients with underlying known deformity. Our extended follow-up highlights the risk factors associated with development of spinal deformity in pediatric IMSCT patients. Surgical fusion allows patients who develop progressive deformity to have long-term functional and survival outcomes that are comparable to those of patients who do not develop progressive deformity.

\section{Disclosure}

The authors report no conflict of interest concerning the materials or methods used in this study or the findings specified in this paper.

Author contributions to the study and manuscript preparation include the following. Conception and design: Menezes, Ahmed. Acquisition of data: Menezes, Ahmed, Awe. Analysis and interpretation of data: all authors. Drafting the article: Menezes, Ahmed, Awe, Mahaney, Torner. Critically revising the article: all authors. Reviewed submitted version of manuscript: all authors. Approved the final version of the manuscript on behalf of all authors: Ahmed. Statistical analysis: Ahmed, Mahaney, Torner. Study supervision: Menezes.

\section{References}

1. Ahmed R, Menezes AH, Awe OO, Torner JC: Long-term disease and neurological outcomes in patients with pediatric intramedullary spinal cord tumors. Clinical article. J Neurosurg Pediatr [epub ahead of print April 4, 2014. DOI: 10.3171/2014/1/PEDS13316]

2. Ahmed R, Traynelis VC, Menezes AH: Fusions at the craniovertebral junction. Childs Nerv Syst 24:1209-1224, 2008

3. Albert TJ, Vacarro A: Postlaminectomy kyphosis. Spine (Phila Pa 1976) 23:2738-2745, 1998

4. Anakwenze OA, Auerbach JD, Buck DW, Garg S, Simon SL, Sutton LN, et al: The role of concurrent fusion to prevent spinal deformity after intramedullary spinal cord tumor excision in children. J Pediatr Orthop 31:475-479, 2011

5. Bell DF, Walker JL, O'Connor G, Tibshirani R: Spinal deformity after multiple-level cervical laminectomy in children. Spine (Phila Pa 1976) 19:406-411, 1994

6. Cobb MA, Boop FA: Replacement laminoplasty in selective dorsal rhizotomy: possible protection against the development of musculoskeletal pain. Pediatr Neurosurg 21:237-242, 1994

7. de Jonge T, Slullitel H, Dubousset J, Miladi L, Wicart P, Illés T: Late-onset spinal deformities in children treated by laminectomy and radiation therapy for malignant tumours. Eur Spine J 14:765-771, 2005

8. Evans AE, Norkool P, Evans I, Breslow N, D’Angio GJ: Late effects of treatment for Wilms' tumor. A report from the National Wilms' Tumor Study Group. Cancer 67:331-336, 1991

9. Fassett DR, Clark R, Brockmeyer DL, Schmidt MH: Cervical spine deformity associated with resection of spinal cord tumors. Neurosurg Focus 20(2):E2, 2006

10. Garcés-Ambrossi GL, McGirt MJ, Mehta VA, Sciubba DM, Witham TF, Bydon A, et al: Factors associated with progression-free survival and long-term neurological outcome after resection of intramedullary spinal cord tumors: analysis of 101 consecutive cases. Clinical article. J Neurosurg Spine 11:591-599, 2009

11. Kaptain GJ, Simmons NE, Replogle RE, Pobereskin L: Incidence and outcome of kyphotic deformity following laminectomy for cervical spondylotic myelopathy. J Neurosurg 93 (2 Suppl):199-204, 2000

12. Katsumi Y, Honma T, Nakamura T: Analysis of cervical instability resulting from laminectomies for removal of spinal cord tumor. Spine (Phila Pa 1976) 14:1171-1176, 1989

13. Klekamp J: Treatment of intramedullary tumors: analysis of surgical morbidity and long-term results. Clinical article. J Neurosurg Spine 19:12-26, 2013

14. Lapinksy AS, Richards BS: Preventing the crankshaft phenomenon by combining anterior fusion with posterior instrumentation. Does it work? Spine (Phila Pa 1976) 20:1392-1398, 1995

15. Lee CS, Nachemson AL: The crankshaft phenomenon after posterior Harrington fusion in skeletally immature patients with thoracic or thoracolumbar idiopathic scoliosis followed to maturity. Spine (Phila Pa 1976) 22:58-67, 1997

16. Lunardi P, Licastro G, Missori P, Ferrante L, Fortuna A: Management of intramedullary tumours in children. Acta Neurochir (Wien) 120:59-65, 1993

17. McAllister BD, Rebholz BJ, Wang JC: Is posterior fusion necessary with laminectomy in the cervical spine? Surg Neurol Int 3 (Suppl 3):S225-S231, 2012

18. McGirt MJ, Chaichana KL, Atiba A, Bydon A, Witham TF, Yao KC, et al: Incidence of spinal deformity after resection of intramedullary spinal cord tumors in children who underwent laminectomy compared with laminoplasty. J Neurosurg Pediatr 1:57-62, 2008

19. McGirt MJ, Garcés-Ambrossi GL, Parker SL, Sciubba DM, Bydon A, Wolinksy JP, et al: Short-term progressive spinal deformity following laminoplasty versus laminectomy for resection of intradural spinal tumors: analysis of 238 patients. Neurosurgery 66:1005-1012, 2010

20. Meyer NJ, Flatley TJ, Dunn DD: Superiorly based lamino- 


\section{Skeletal deformity and pediatric intramedullary tumors}

plasty in children: average 6.8-year follow-up of 21 patients. J Spinal Disord Tech 16:156-162, 2003

21. Otsuka NY, Hey L, Hall JE: Postlaminectomy and postirradiation kyphosis in children and adolescents. Clin Orthop Relat Res (354):189-194, 1998

22. Papagelopoulos PJ, Peterson HA, Ebersold MJ, Emmanuel PR, Choudhury SN, Quast LM: Spinal column deformity and instability after lumbar or thoracolumbar laminectomy for intraspinal tumors in children and young adults. Spine (Phila Pa 1976) 22:442-451, 1997

23. Papin P, Labelle H, Delorme S, Aubin CE, de Guise JA, Dansereau J: Long-term three-dimensional changes of the spine after posterior spinal instrumentation and fusion in adolescent idiopathic scoliosis. Eur Spine J 8:16-21, 1999

24. Ratliff JK, Cooper PR: Cervical laminoplasty: a critical review. J Neurosurg 98 (3 Suppl):230-238, 2003

25. Rauzzino MJ, Shaffrey CI, Wagner J, Nockels R, Abel M: Surgical approaches for the management of idiopathic thoracic scoliosis and the indications for combined anterior-posterior technique. Neurosurg Focus 6(5):E6, 1999

26. Robinson D, Galasko CS, Delaney C, Williamson JB, Barrie JL: Scoliosis and lung function in spinal muscular atrophy. Eur Spine J 4:268-273, 1995

27. Shikata J, Yamamuro T, Shimizu K, Saito T: Combined laminoplasty and posterolateral fusion for spinal canal surgery in children and adolescents. Clin Orthop Relat Res (259):9299, 1990

28. Simon SL, Auerbach JD, Garg S, Sutton LN, Telfeian AE, Dormans JP: Efficacy of spinal instrumentation and fusion in the prevention of postlaminectomy spinal deformity in children with intramedullary spinal cord tumors. J Pediatr Orthop 28:244-249, 2008

29. Tachdjian MO, Matson DD: Orthopaedic aspects of intraspinal tumors in infants and children. J Bone Joint Surg Am 47: 223-248, 1965

30. Thomas PR, Griffith KD, Fineberg BB, Perez CA, Land VJ: Late effects of treatment for Wilms' tumor. Int J Radiat Oncol Biol Phys 9:651-657, 1983

31. Watanabe K, Hasegawa K, Hirano T, Uchiyama S, Endo N:
Evaluation of postoperative residual spinal deformity and patient outcome in idiopathic scoliosis patients in Japan using the Scoliosis Research Society Outcomes Instrument. Spine (Phila Pa 1976) 32:550-554, 2007

32. Yang S, Yang X, Hong G: Surgical treatment of one hundred seventy-four intramedullary spinal cord tumors. Spine (Phila Pa 1976) 34:2705-2710, 2009

33. Yao KC, McGirt MJ, Chaichana KL, Constantini S, Jallo GI: Risk factors for progressive spinal deformity following resection of intramedullary spinal cord tumors in children: an analysis of 161 consecutive cases. J Neurosurg 107 (6 Suppl): 463-468, 2007

34. Yasuoka S, Peterson HA, Laws ER Jr, MacCarty CS: Pathogenesis and prophylaxis of postlaminectomy deformity of the spine after multiple level laminectomy: difference between children and adults. Neurosurgery 9:145-152, 1981

35. Yasuoka S, Peterson HA, MacCarty CS: Incidence of spinal column deformity after multilevel laminectomy in children and adults. J Neurosurg 57:441-445, 1982

36. Yeh JS, Sgouros S, Walsh AR, Hockley AD: Spinal sagittal malalignment following surgery for primary intramedullary tumours in children. Pediatr Neurosurg 35:318-324, 2001

37. Zdeblick TA, Abitbol JJ, Kunz DN, McCabe RP, Garfin S: Cervical stability after sequential capsule resection. Spine (Phila Pa 1976) 18:2005-2008, 1993

Manuscript submitted June 24, 2013.

Accepted January 27, 2014.

Portions of this work were presented in a poster presentation format at the Annual Meeting of Congress of Neurological Surgeons, Chicago, Illinois, October 6-10, 2012.

Please include this information when citing this paper: published online April 4, 2014; DOI: 10.3171/2014.1.PEDS13317.

Address correspondence to: Arnold H. Menezes, M.D., Department of Neurosurgery, University of Iowa Hospitals and Clinics, 200 Hawkins Dr., 1824 JPP, Iowa City, IA 52242. email: arnoldmenezes@uiowa.edu. 